\title{
IMMERSIVE TECHNOLOGY AS A CREATIVE TOOL FOR CRITICAL DESIGN AND ENHANCED RESEARCH METHODS IN EDUCATIONAL DESIGN PROGRAMS
}

\author{
Eduardo Xavier García \\ MDes, Centro de Diseño, Cine y Televisión, MÉXICO, egarciac@centro.edu.mx
}

\begin{abstract}
The world is experiencing a momentous surge in advanced immersive technology that has generally been excluded from classrooms due to a variety of reasons, including the exorbitant costs associated with it. With developers flooding the market offering competing peripherals, prices are dropping significantly making the technology accessible to educational institutions. My research investigates how schools can begin to use extended reality technology as a creative tool in educational design programs and how it offers students critical design methods and enhanced research processes.

For this research I conducted a literature review and designed and carried out a case study with high school design students at a private school in Mexico City. The study adopted an empirical methodology to provide both qualitative and quantitative data. It was designed to measure students' engagement and experience developing virtual environments while evaluating the pedagogical approach used to design instruction. It is worth noting that the case study was realized while in remote learning during the pandemic in the spring 2021 so this could be considered a limiting factor in the study's results. After completing their projects, students were surveyed and results suggest that students engaged in their learning while using immersive technology as a creative tool. They felt confident that they retained the content learned and that they would apply the methods used across other contexts, in and out of the classroom.

Design programs that implement extended reality can empower students to not only imagine and speculate design solutions, but to actually experience them as virtual prototypes. This can support the discovery of innovative approaches to problem resolution, research, and building new knowledge, fostering long-lasting critical thinking skills.
\end{abstract}

Keywords: critical design, design education, educational technology, extended reality, pedagogy

\section{INTRODUCTION}

In recent years, STEAM (Science, Technology, Engineering, Arts, and Math) programs, Ed-Tech, and makerspaces have become important trending topics in the education community. My hope is that the research presented here can add to the conversations about what we know works in education and propel it 
forward by developing innovative teaching and learning methods. With extended-reality technology teachers and students can create virtual environments of active learning that inspires them to be the critical designers and creators of a better tomorrow.

The aim of this article is to propose and share new approaches to teaching that teachers can implement in their teaching practice to foster rich learning experiences. The research focuses primarily on immersive technology and how it can offer students and teachers critical design methods and enhanced research processes. What I propose is not new because it is rooted in familiar pedagogy. What is new is the manner in which immersive technology is fast-evolving and becoming affordable for educational institutions to implement. My intention is to highlight some of these immersive educational-technology resources and to demonstrate, how paired with the appropriate pedagogical approach, teachers can design instruction that engages students in the discovery of innovative approaches to problem solving, research, building new knowledge, and fostering long-lasting critical thinking skills.

In section two I discuss the state of immersive technologies and related components to show their accelerated evolution in the past few years. In section three I present a review of academic papers, articles, books, and videos that look at how these technologies have been and are being implemented in educational programs. Section four offers a look at "immersive technology as a creative tool in the design classroom." For this I conduct a brief analysis on pedagogy to determine which can best support teachers when designing instruction that implements immersive technologies. I address how teachers can take a creative approach with this technology so that students are empowered to not only imagine and speculate design solutions, but to actually experience them as immersive virtual prototypes. In section five I present the case study of the Transmedia and Creative Technology high school class in Mexico City where I measured student engagement, their experience developing virtual environments, and evaluated the pedagogical approach applied in instruction design. In the final section I present conclusions and invite continued discussion on how learning institutions are implementing immersive technologies in the classroom and making them available to teachers.

\section{IMMERSIVE TECHNOLOGY DEVELOPMENTS, AND EDUCATIONAL ACCESSIBILITY}

Virtual reality is defined by Radianti et al. (2020) as "the sum of the hardware and software systems that seek to perfect an all-inclusive, sensory illusion of being present in another environment" or in a non-physical world. The concept of immersive technology has been around since before the 1960's making early appearances in the entertainment industry (Jensen \& Konradsen, 2017). In 1962, American cinematographer Morton Heiling designed and prototyped the "Sensorama Simulator." This is considered to be one of the earliest efforts at virtual reality where the goal was for users to experience a sense of immersiveness (Merchant et al, 2014). Since then, the development of immersive technology has been somewhat slowmoving. The ideas were there, but the computing power required to drive those ideas lagged. The past two decades have seen some exciting developments in technology, and demands coming from the entertainment industry have catapulted the development of the technology to move at an exponential rate. Examples of these are game engine software packages like Epic's Unreal Engine, 64-core Threadripper Pro CPU processors by AMD, and ultra fast GPUs like NVIDIAs RTX 3090. Developments in the technology have been driven primarily by the entertainment industry, specifically by gaming-tech enterprises which have a colossal global customer and user base estimated to be around 2.7 billion clients. The industry sees multibillion dollar profits grow annually and generated estimated revenues of $\$ 153$ billion USD in 2020 and are expected to surpass $\$ 200$ billion by 2023 (Wijman, 2020). Customers demand faster processing and computing power from their devices to render more realistic and immersive gaming experiences. This has created a highly competitive market where new players and start-ups are joining the race, making the market more competitive than ever. Big tech companies such as NVIDIA, AMD, and Intel are investing a great deal of resources to improve their products, position themselves at the top, and win over the demand of the vast client base. This has compelled tech companies to design exceedingly faster and better quality consumergrade products. In the last decade or so companies have made significant strides and investments in making these technologies faster, more practical, more immersive, more interactive, more realistic, more ergonomic, and most importantly more affordable to consumers. This technology that was essentially priced out-of-reach for the public and education institutions, has now become affordable for the average consumer, particularly "gamers," content creators for games, large and independent film studios, amongst others in the entertainment industry. However, another sector that has taken note of these important developments is education, specifically educational institutions with programs focused in science, architecture, engineering and design (Radianti et al., 2020). 
Students, teachers and educational institutions can begin to implement immersive technologies through educational licensing at reduced pricing and open source software and alternative VR options like the Google Cardboard HMD. This is allowing design and makers labs in schools to purchase and make use of them as tools for teaching and learning. The computational power is much more than what was possible five to ten years ago. Realistic, real-time physical rendering is now possible in a consumer laptop or desktop computer. Graphics processors and Apple's M1 chip technologies are revolutionizing home computing and the way institutions and students can design using these tools, offering them advanced prototyping capabilities and large data visualizations never before seen in high school classrooms. As these technologies become accessible to educational budgets and teachers become familiarized with the (practicality of the) technology, learning institutions are giving serious consideration to the technology. But we should also acknowledge the tremendous advertising pressures coming from the tech industry itself. There are huge profits to be made by these tech companies if they tap into the education sector. Education administrators must keep in mind that behind real authentic learning experiences there are great teachers and without them the technology is useless.

\section{STATE OF THE ART - SPECIALIZED LITERATURE REVIEW}

In this section I discuss the specialized literature review conducted on immersive technologies in education. Searches were performed on several academic databases using a combination of the following search strings: "Augmented Reality in Education", "Design Education", "Immersive Technology in Education", "Unreal Engine in Education", "Virtual Reality in Education". From the search, 52 papers were found and 11 papers were reviewed. These were selected because in their abstracts they addressed the following as common technologies and concepts in education: Augmented Reality, Extended Reality, Game Engines, Head Mounted Display, Immersive 3D Technology, Virtual Environments, Virtual Prototype, Virtual Reality. This investigation also reviewed recent web articles published within the last 24 months spanning from 20192021 and several TED talks on education.

\subsection{Context of Immersive Technology in Education}

Virtual reality and immersive technologies have been around for a few decades now and until recently, they've generally been kept out of education. But educators are beginning to explore the potential contributions these technologies can offer to instruction and curricular programs (Reiners et al., 2014). In the last few decades it was believed that immersive technologies would change the way education is delivered. It was in the 1990's that the education sector began to implement early versions of the technology in both K-12 and higher education institutions, but this technology has generally been excluded from the toolset of teachers and classrooms (Merchant et al., 2014). The designs of the peripherals associated with the technology were simply too impractical; HMDs were large, heavy, had low-ergonomic design, low level of reliability, low fidelity and low resolution graphics. A big drawback was that the technology was too slow and had high-latency, meaning it would not track the users' movements in real-time. Another issue was a teacher would have to go through extensive training to learn how to use the technology. For these reasons schools had rendered the technology unusable for educational settings (Jensen \& Konradsen, 2017). Besides the unworkability of the technology, the high price tag attached to the technology made it available only to highly funded research laboratories at select universities. But this has been and is changing at a very rapid pace in the last five-to-seven years. As the technologies continue to see significant improvements and lower prices, schools are beginning to implement and materialize consumer-grade immersive technology into their educational programs (Jensen \& Konradsen, 2017).

Today's consumer-grade immersive technologies offer highly ergonomic design and precise real-time tracking of the user's movements in virtual environments. High-fidelity realtime renderers such as Unreal Engine offer users realistic virtual worlds. Combined with real-time motion capture suits such as the Rokoko, users can truly feel that they are immersed in virtual environments. The learning curve to use these technologies has also come a long way. The technology is much more intuitive and user-friendly. This can be seen in the gaming industry where gamers learn how to use these technologies on their own for recreational purposes. Another consideration is that as younger generations enter the teaching profession, more of them already have experience using some of these technologies. High-speed internet connectivity has also propelled these technologies to thrive as content, heavy software packs, and resources can now be streamed or downloaded instantly into classrooms. Additionally, this high-speed connectivity opens the possibilities for students and teachers to work collaboratively in virtual environments (Merchant et al., 2014). As these technologies continue to see significant design improvements, they are becoming more feasible for educational institutions to begin to implement them. 


\subsection{History, Benefits, and Drawbacks of Immersive Technology in Education}

Starting around the 1990s scholars began to explore the benefits of implementing immersive technologies in education for research purposes, primarily in the areas of engineering, architecture, industrial design, vocational training and in the private sector for job training purposes (Radianti et al., 2020). Implementing immersive technologies as creative tools at the $\mathrm{K}-12$ grade school level is underexplored and underresearched (Häkkilä et al., 2018). As the consumer-grade immersive technology becomes available to learning institutions, they are entering a new phase where it is used as a creative tool and not just as monitor or interface alternatives; students can now build content for virtual worlds. Until recently immersive technology has been used with students for the occasional class VR field trip, or virtual class meetings. Now, one of the greatest benefits of using immersive VR technology is the ability for students to be able to quickly prototype their designs with ease, experience them, and manipulate them in an immersive environment. Students can simulate, test, and interact with their virtual prototypes in real-time. If a design proves to need further modification, a student can quickly make changes to the design and re-prototype without spending too much time and physical material rebuilding several iterations of the design (Aromaa et al., 2016). These designs or virtual simulations can be experienced and tested in an immersive manner locally or remotely.

In a meta review of immersive technology education papers, it was summarized that it has been effective for improving learning performance, learning motivation, student engagement and positive attitudes (Häkkilä et al., 2018). When a student is truly engaged in a learning activity, new knowledge is retained; true learning happens when learners create meaning from their experiences. Immersive technologies have the ability to allow students to live, experience, and involve themselves in the learning process (Freina et al., 2015). There is a significant improvement in content understanding, long-term memory retention, collaboration and student motivation (Häkkilä et al., 2018). A recent article suggested that students remember $20 \%$ of what they see and $30 \%$ of what they hear in class, but up to $90 \%$ of what they learn through immersive experiences (Vlasova, 2020).

Immersive technology is not without its flaws, as the research also shows. One of the drawbacks of the technology is that not all students will thrive in learning through immersive technology. Teachers must be able to differentiate their approaches to their instruction and accommodate the learning styles and abilities of different students. Another drawback is once the novelty of the technology wears off, students can become uninterested. This is why it is important to consider how the technology is used and to avoid repetitive activities (Häkkilä et al., 2018). The technology can be best taken advantage of if it is used as a creative tool where teachers and students are creating content for and with the technology (Jensen \& Konradsen 2017). A third drawback noted is the possibility that technology becomes a distraction from the content being learned. This can be caused by the unfamiliarity of the technology or by inadequate pedagogical consideration when designing instruction for the technology. Case studies on programs that have introduced immersive technologies into design education have demonstrated the shortcomings and how these relate to the pedagogical approach and instructional design (Dalgarno et al., 2013).

\section{PEDAGOGY AND INSTRUCTION DESIGN FOR THE TECHNOLOGY AS A CREATIVE TOOL}

One of my primary interests in this research was to investigate how immersive technologies can support teachers in providing rich learning experiences for students. In conversation with my research tutor and colleague, Andres Lombana Bermudez, $\mathrm{PhD}$, he agreed that immersive technologies are important educational tools. However, he suggested I consider pedagogy and recommended bringing in "pedagogy and learning approaches and putting them in dialogue with the technology." This helped me to identify which educational learning theories are best suited to make use of the technology in teaching.

\subsection{Pedagogy}

Because these technologies require students to physically engage to play an active role in their learning, they are ideal constructivist learning tools. According to constructivist theory, direct experiences between the mind and the environment are critical for meaning to be created (Ertmer \& Newby, 1993). The teacher who designs instruction for immersive technology facilitates the process of students connecting mind, body, and "virtual environment." Today's immersive technology allows learners a level of highly realistic experiences where the student is immersed in a high-fidelity, low-latency virtual environment to design and work in. Students can work in simulated virtual environments to evaluate feasibility and identify flaws without realworld consequences or setbacks. Virtual prototyping can also allow for students to experience and interact with their designs and iterate as many times as needed without wasting time or materials (Jensen \& Konradsen 2017). This can be seen as experiential learning whereby the students are learning from their 
interactions within the virtual worlds. And the compelling element of this is that there are no limitations to what students can research because the technology will allow them to create and simulate any environment. Education theorist John Dewey called on educators to provide children with "first-hand experiences." I believe that these immersive technologies offer students experiences that support their learning process.

Immersive technology as a creative tool can be used in a manner in which students become content creators and manipulators (Arhippainen et al., 2011). Practice-based learning or practice-based research fosters student metacognition, supporting students' learning of design, learning through design practice, or learning from design objects they create. An important consideration when implementing immersive technology is that it grants students the ability to practice building content, prototype virtually, and conduct extensive iteration on designs efficiently. The technology can support students to understand the thinking processes that led them to create such designs. Through practice within virtual environments and tools that would otherwise be inaccessible to them, students learn to not only create their own designs, but also to richly understand the entire process. This process allows the students to become aware of the knowledge that they are building through their own practice, a key component of metacognition. They become active participants in their learning, fostering the appropriation of the newly built knowledge. No longer are they outsiders "of the knowledge" but active participants of building knowledge... their own knowledge (Mäkelä \& Nimkulrat, 2011).

A design studio pedagogy is another valuable approach to teaching and learning using immersive technology. This pedagogical approach can be traced back to the Bauhaus where technology was employed to teach design. The basis of the design studio approach includes starting with a design problem, concept development, critiques, reviews, followed by iterations of designs (Arida, 2010). A design studio approach is defined by giving students a studio space or workshop where students can explore and inquire about the world around them freely. If we introduce a parallel version of this using immersive technology, students can work in virtual studio environments to freely design and create openly without physical or real world imitations. Students can go as far as to speculate and operate as critical designers whereby they can truly challenge design norms. In the prototyping stage of the design process, immersive technology can allow students to test their designs and iterate them as needed without the setbacks of materials and other physical world limitations. Critiques can take on a whole different dimension as the teacher and peers can experience virtual prototypes, interact with them and provide feedback in and outside of the virtual environment. When it comes time to physically produce a design, it has already been tested virtually so students and teachers can proceed confidently using minimal resources.

\subsection{Instructional Design}

Even though the technology has seen some important and significant improvements, the design of instruction and the pedagogical approach remains a critical factor in effectively utilizing these tools in the classroom. If the technology is not strategically implemented, then it can become a distraction for both teachers and learners alike (Jensen \& Konradsen, 2017). As institutions consider implementing these tools, there needs to be equal consideration for professional development for instructors. Educational institutions must identify educators in their faculty who are willing and excited to take on the challenge of learning how to use the technology effectively. A teacher must be able to create a dynamic environment and design diverse learning approaches that foster student engagement in their learning experiences. Likewise, not all students will thrive learning on these technologies, so it is important to consider the learning styles and individual personalities of students (Arhippainen et al., 2011).

One of the biggest challenges for teachers and students is to engage in genuine learning experiences whereby students can have a meaningful connection with their learning (Thompson, 2019). Immersive technologies can be a great resource for teachers to help students engage meaningfully with their learning. The key is to find a way to make use of these technologies so that the learner is truly engaged and experiences true learning. Teachers must design a curriculum that excites and motivates students to be active participants in their learning. As students work in these environments, they can be allowed to explore openly their creativity and innovate past what is possible in the real world. They should be able to prototype impossible designs, experience simulations of alternate realities that cannot otherwise be perceived. This is why these tools offer an exciting component to the classroom of the future making them spaces of unlimited possibilities (Merchant et al., 2014). The collaborative opportunities possible by immersive technology offer students the ability to engage in developing complex projects that require input and discussion from students with a variety of strengths, abilities and experiences. This makes the learning through the use of the technology a very socially active practice where not one individual can carry out a project. For students to succeed on elaborate projects using these technologies will require them the ability to exchange ideas, be open to feedback and critique, and negotiate their relationship with one another (Arida, 2010). 


\section{CASE STUDY}

In order to evaluate the implementation of immersive technology in practice, I conducted a case study with my Transmedia \& Creative Technology high school students at a private school in Mexico City. The aim of the study was to measure student engagement and experience while developing immersive virtual environments. The secondary aim of the study was to evaluate the pedagogical approach used in designing instruction. It is worth noting that the case study was realized in remote learning modality via Zoom during the COVID-19 pandemic, spring 2021. This could be considered a limiting factor in the study's results due to the fact that students only had access to the technology and resources they had at home. Another variable is that students worked on personal computers at home so they all had systems with different computing capabilities (Windows vs. Mac \& laptop vs. desktop).

\subsection{Methodology}

The case study was conducted over a period of six weeks with a class of 16 students: 4 female (F) \& 12 male $(M) ; 9=9$ th graders, $6=10$ th graders, $1=11$ th grade. All students were under the age of 18 so parents were notified of the case study and were asked to grant consent for their children to participate in the study. Only one student had previous but limited experience building virtual environments using the software Blender. The other students were beginners. Because we did not have access to the VR technology on campus, I asked students to purchase the Google Cardboard VR HMD (\$15 USD); six students purchased it and two students owned an Oculus VR HMD. The remaining 8 students viewed the content on their computer screens. All students acquired a Maxon One educational license (\$3USD) which granted them access to Cinema 4D (C4D) for six months. The After Effects (AFX) license is provided to each student by the school while they are enrolled in the course. Students engaged in a unit that required them to build a virtual environment that was to be experienced and viewed using an HMD. They had to conceptualize a world that they would build on their computers using only the software mentioned above. In creating an immersive virtual environment, students were asked to consider the following prompts:

- Design a place or environment
- An unreachable place (e.g. exoplanet, inside of volcano, time travel)
- Prototyped space to assess functionality (e.g. public park, interior of a building)
- Speculative or imaginary place

- Consider the user/viewer role in the environment

- What will the role of the user/viewer be?

- Will the immersive experience take the user/viewer on a "ride" or will they simply be static and observe the environment?

- What will the scale of the user/viewer be in relation to the environment?

- Audio/sound

- What will users hear in the virtual environment?

- How will the audio enhance the immersive experience for viewers/users?

To produce their virtual environments, students used native 3D objects available in C4D and additional free assets from the websites Sketchfab, Turbosquid, and for those students with more capable systems, Megascans. Once the students built their virtual environments in C4D, they imported them to AFX, and then exported them as immersive VR videos. Finally, students uploaded their immersive content to YouTube and shared them with their classmates so that they could experience them using VR HMD. To learn how to make their content VR, students followed a tutorial by VR Visage available on the YouTube channel "New Tech Tutorials" (https://youtu.be/NtlorayJc4o). The video instructs on the general steps on how to produce, render, and publish immersive videos to YouTube to be viewed as VR.

The study adopted an empirical methodology to produce qualitative and quantitative data that provided insights into how students perceive learning experiences with these technologies. For the qualitative data semi-structured, ethnographic interviews were conducted as a class discussion to gain insights into student perspectives towards the unit task. For the quantitative data collection, after students submitted their completed projects for the unit, they were surveyed on a likert scale format questionnaire on a Google form. 11 out of the 16 responded to the survey. The survey consisted of 25 questions broken up into four sections. 
Each section sought to measure a different parameter.

Section 1 - Student Engagement with Building Environments: This section sought to measure student enjoyment and interest in learning to design and build immersive 360 virtual environments. Section 2 Student Experiencing Immersive Virtual Environments: This section sought to measure students' desire to share their environment with other students, as well as their desire to experience immersive environments produced by the other students. Section 3 - Student Experience Working with Software and Hardware: This section sought to measure how students associated the experience of building virtual environments to the software and hardware they worked with. Section 4 - Student Understanding and Retention of Content Learned: This section sought to measure how well students understood the content and to what extent they felt confident that they retained what they learned.

\subsubsection{Pedagogy and Instruction}

To begin the unit, students first conducted formal analysis of existing VR experiences on YouTube. They evaluated them, identifying what elements make an effective immersive experience (animation, scale, lighting, sound design), and what types of environments are best suited for immersive virtual experiences. Students were then asked to produce a comprehensive storyboard that described what the elements of their experiences would be. They then designed a plan that ensured efficient use of their time and resources. In their plan students had to justify the feasibility of their project and include specific details about their immersive virtual experience. Through a series of demo exercises on C4D via Zoom, students were introduced to the software tools and how to work and animate. But students mainly worked independently, allowing them to practice and make connections with the tools and experience them first hand. They were given absolute freedom to choose what type of world they would build.

\subsubsection{Assessment of Student Projects}

Students were assessed on the following criteria using the following rubric.

\begin{tabular}{|l|l|l|l|}
\hline \multicolumn{1}{|c|}{ Scoring Criteria } & \multicolumn{1}{|c|}{ Positive } & \multicolumn{1}{|c|}{ Average } & Poor \\
\hline 1. Environment & $\begin{array}{l}\text { Constructs complete virtual } \\
\text { environment demonstrating } \\
\text { excellent technical skills }\end{array}$ & $\begin{array}{l}\text { Constructs partial virtual } \\
\text { environment demonstrating } \\
\text { competent technical skills }\end{array}$ & $\begin{array}{l}\text { Environment is incomplete } \\
\text { or poorly constructed } \\
\text { demonstrating minimal } \\
\text { technical skills }\end{array}$ \\
\hline $\begin{array}{l}\text { 2. User role and } \\
\text { navigation }\end{array}$ & $\begin{array}{l}\text { There is a clear and logical } \\
\text { way for the user to navigate } \\
\text { in the environment }\end{array}$ & $\begin{array}{l}\text { The role of the user and } \\
\text { navigation in the environment } \\
\text { is partially clear }\end{array}$ & $\begin{array}{l}\text { The role of the user in the } \\
\text { environment is uncertain } \\
\text { and there is no clear sense } \\
\text { of direction }\end{array}$ \\
\hline $\begin{array}{l}\text { 3. User scale vs } \\
\text { environment }\end{array}$ & $\begin{array}{l}\text { The scale of the user vs the } \\
\text { environment is created } \\
\text { appropriately }\end{array}$ & $\begin{array}{l}\text { The scale of the user vs the } \\
\text { environment is partially } \\
\text { adequate and satisfactory }\end{array}$ & $\begin{array}{l}\text { The scale of the user vs } \\
\text { elements in environment } \\
\text { was inadequate }\end{array}$ \\
\hline $\begin{array}{l}\text { 4. Sound } \\
\text { implementation }\end{array}$ & $\begin{array}{l}\text { Sound is designed to } \\
\text { enhance the virtual } \\
\text { environment's } \\
\text { immersiveness }\end{array}$ & $\begin{array}{l}\text { Sound consideration is } \\
\text { somewhat appropriate for the } \\
\text { environment }\end{array}$ & $\begin{array}{l}\text { Sound is minimal or is } \\
\text { missing in the virtual } \\
\text { experience }\end{array}$ \\
\hline
\end{tabular}

Out of the 16 students, 5 completed the project with positive results; 5 completed the project with average results; 4 completed the project with poor results; 2 did not complete a functioning project. The five students with the best results produced immersive worlds of virtual environments that offered users a convincing immersive experience. Student \#1/M produced a surrealist environment that gave users the experience of what it would be like to be in a Dali-Surrealist painting. Users were taken on a walk through a sort of a garden and if they looked up there was a mirrored world in the sky. The sounds in the environment were calm and bird chirping could be heard. This added a very effective immersive quality to the environment. Student \#2/M produced a virtual recreation of a school campus outside of London where he had gone to school a few years earlier. He relied on memory and Google Maps to guide the recreation. The tour first took 
viewers around the neighborhood and then to the recreational areas that included sports fields (Fig.1). Student \#3/M took users on a tour of the inside of a spaceship from the game Among Us (Fig.2). The movement of the user throughout the spaceship was quite fast so it was difficult to clearly inspect the environment but it was evident that it was well constructed. The student included the sound of footsteps and the constant sound of a machine hum to the experience, making it more authentic. Student \#4/F took users on a hot-air balloon ride in mountainous terrain. The experience felt convincing because users could see mountains, clouds, and other balloons floating around in the environment. The student also included the sound of flame that one hears when riding on a hot air balloon. Student \#5/F produced three scenarios in which users could "face their fears." There were three scenarios: standing in a room with closing-in walls, standing on railroad tracks as a train neared, and walking off a plank from a high rise building. The student incorporated sound design really well: in the railroad scene the train could be heard far away and it got louder as it was getting closer; in the scene with the walls closing in, there was a sound of the concrete walls dragging on the floor as they closed in on the user; in the third scene, where the user was on the rooftop of a building, wind was heard blowing and birds chirping as they flew by.
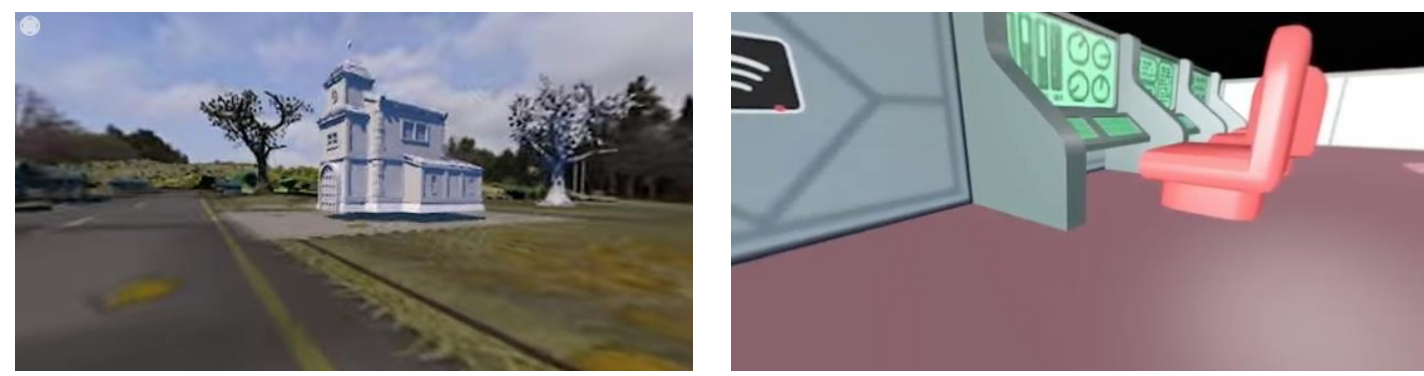

Fig. 1 (left): Student \#1/M recreation of the campus of a school he formerly attended in London. Fig. 2 (right): Student \#3/M recreation of the inside of the spaceship from the game "Among Us."

\subsection{Study Results}

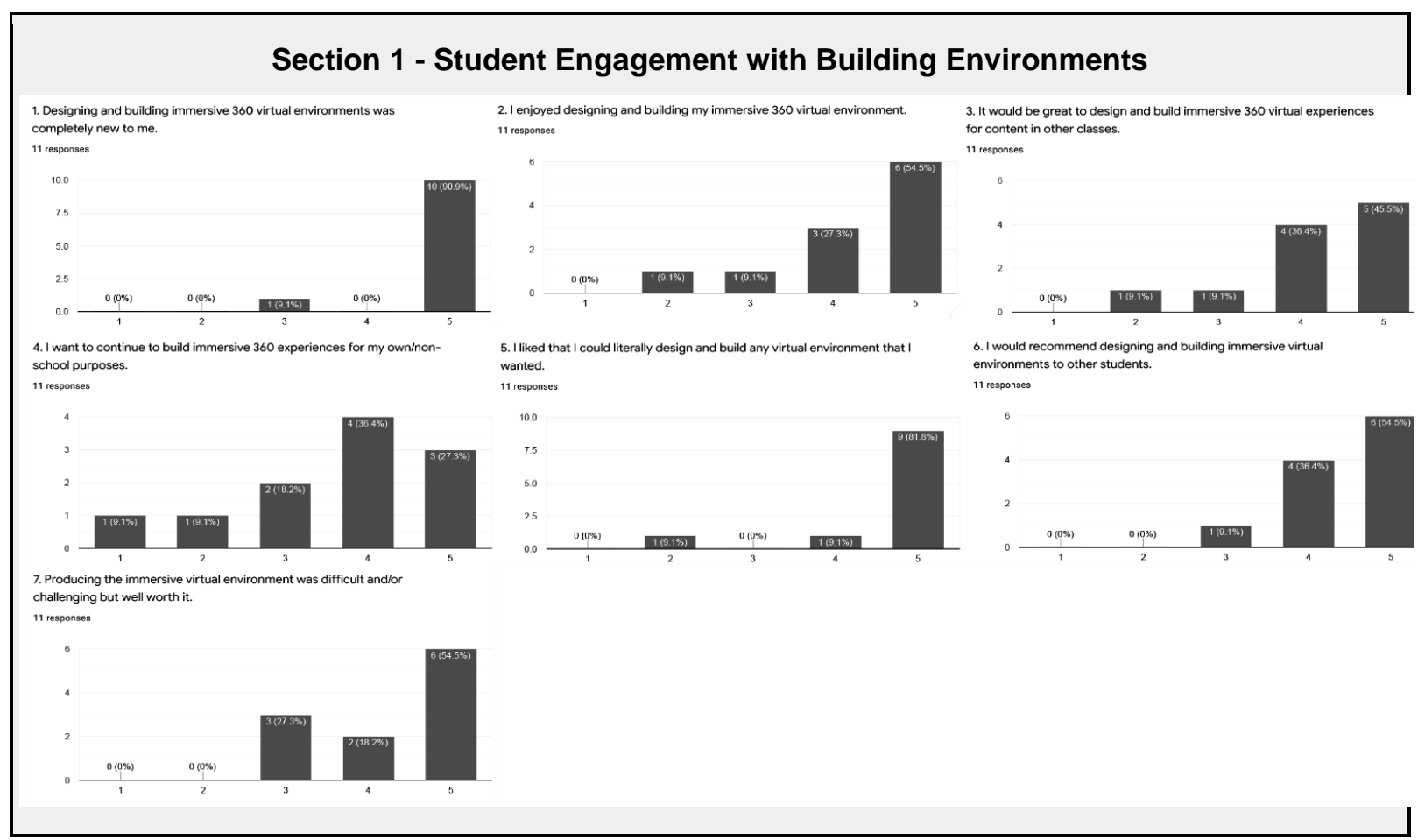



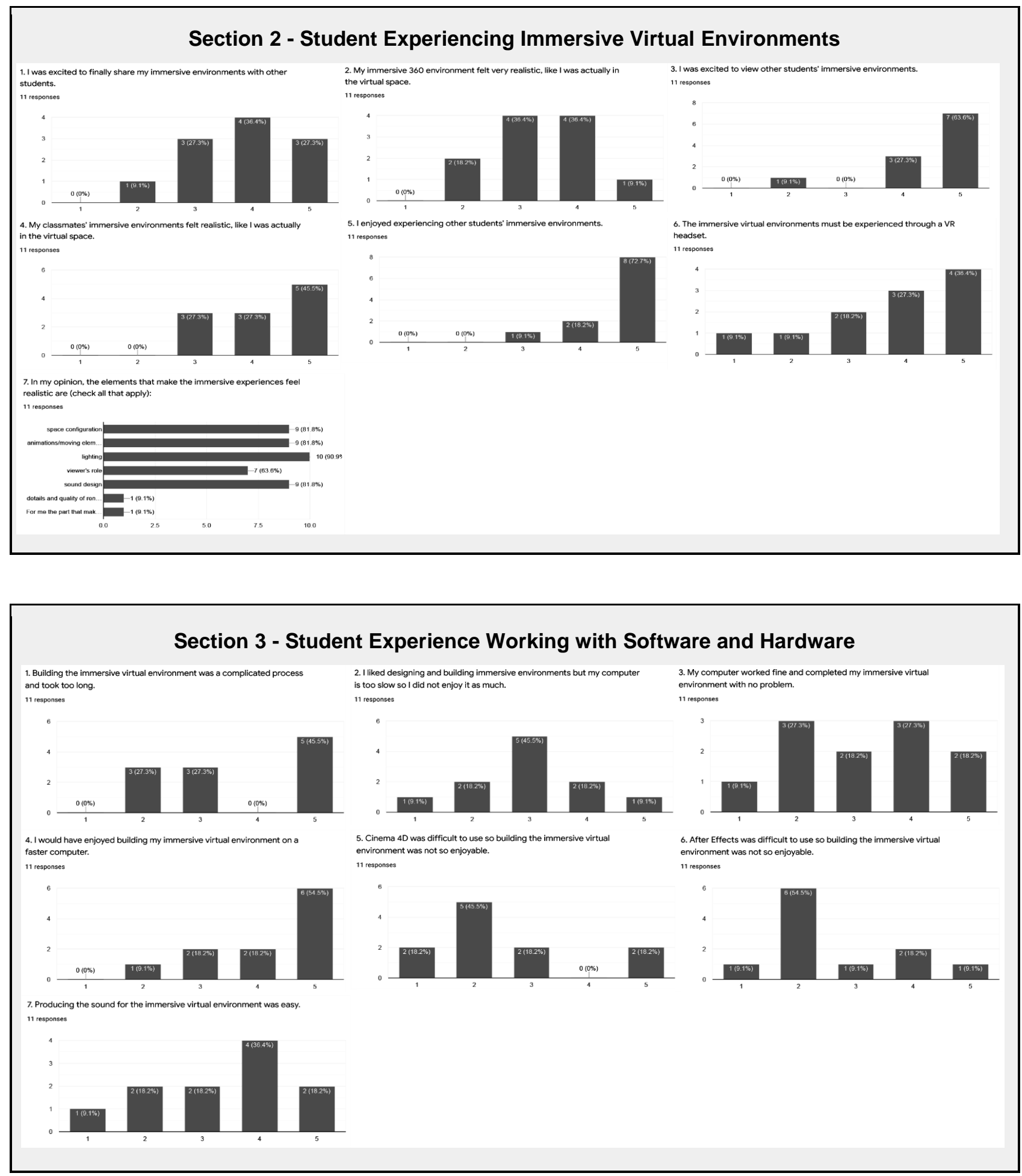


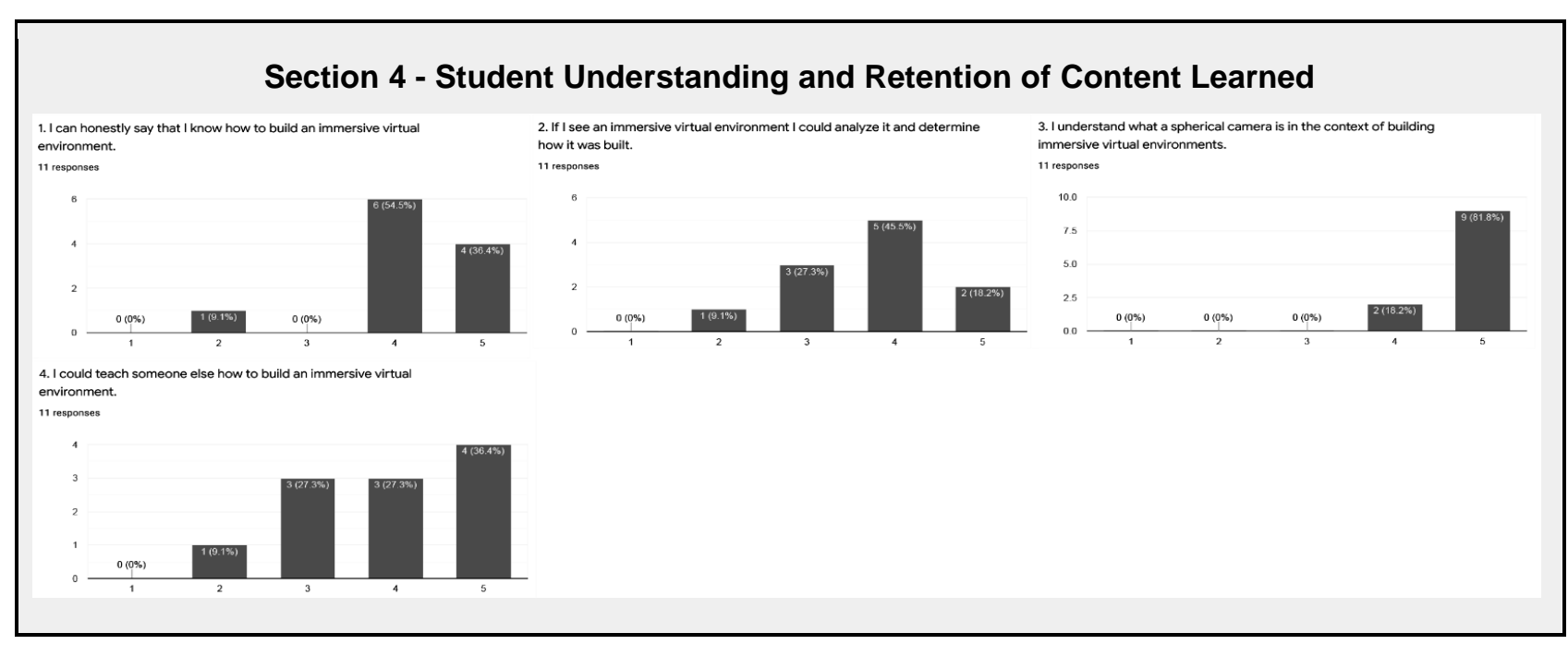

The results from each of the sections of the survey were averaged and calculated into percentages to determine whether the students felt positive, neutral or negative towards the parameter during the unit.

\begin{tabular}{|l|c|c|c|}
\hline \multicolumn{1}{|c|}{ Conceptual parameter } & positive & neutral & negative \\
\hline 1. Student engagement with building virtual environments & $82 \%$ & $12 \%$ & $6 \%$ \\
\hline 2. Student experiencing peer immersive virtual environments & $71 \%$ & $20 \%$ & $9 \%$ \\
\hline 3. Student experience working with software and hardware & $42 \%$ & $22 \%$ & $36 \%$ \\
\hline 4. Student understanding and retention of content learned & $80 \%$ & $14 \%$ & $7 \%$ \\
\hline
\end{tabular}

The survey results suggest that students were engaged in their learning while using immersive technology as a creative tool. They felt confident that they retained the content learned and that they would apply the methods used across other contexts, in and out of the classroom. The survey found the parameter to be most balanced or negative was the experience students had working with the software and hardware. This could be attributed to the fact that students were working remotely from home on basic computer systems and did not have the immediate support of a teacher or peer. Through the semi-structured interviews, students expressed that overall they enjoyed the unit. Developing virtual environments for VR was something that they had never done before and were excited at the opportunity. Their comments aligned with their responses on the survey. Those that did not complete the project successfully were able to express that they experienced problems with the software running slow on their computers. This led them to feel frustration towards the project and led them to dedicate little additional time to it. Because the class was in remotelearning modality, these students felt that they did not receive the appropriate support on the project.

\section{CONCLUSIONS AND DISCUSSION}

In this paper, I have discussed what immersive technology is, where and how it has worked for institutions and teachers spearheading its implementation as a creative tool in the classroom. As the market continues to be flooded with consumer-grade hardware of these technologies, teachers and educational institutions will continue to implement them into their method of instruction and classrooms. There are a wide variety of companies that offer educational licensing (free or reduced prices) of their software to students and teachers, thus democratizing it and allowing teachers to implement it in their practice.

It is evident that the technology requires teachers who want to use it to guide students with instruction designed and grounded strongly in learning theories that work well with it. If the instruction is not well 
designed for the technology, students will more than likely not see the benefit of the technology and quickly lose interest and disengage from the learning. The case study helped to gauge how the technology can engage students in their learning. The students overwhelmingly enjoyed the process of conceptualizing and producing environments that they could then share amongst themselves without the limitations of the physical world. They felt they retained what they learned and were likely to apply it to projects outside of the course, perhaps in other classes. Ultimately, the case study also allowed me to gain a student perspective and understand how they perceived working with these technologies. There were some limitations to the study, including it being done in a remote learning modality, students not having access to standardized technology, and not having a teacher present to support them when they ran into challenges with the technology. Another thing to note is that this was a very small sample and the results cannot be generalized. Further research is needed to determine how teachers can fully integrate these technologies to offer students authentic learning experiences.

I hope that the research presented here is useful for teachers and institutions pursuing the use of immersive technology. My goal in presenting this paper is that the information is built upon to create a framework that can then be replicated, transferred, and adapted to new scenarios. This research hopefully will foster further development of design labs and makerspace programs at the grade school level which will offer students critical design and enhanced research methods.

\section{REFERENCE LIST}

Arhippainen, L., Pakanen, M., Hickey, S., \& Mattila, P. (2011). User experiences of 3D virtual learning environment. Proceedings of the 15th International Academic MindTrek Conference on Envisioning Future Media Environments - MindTrek '11, 222-227. https://doi.org/10.1145/2181037.2181075

Arida, S. (2010, February). More seeing in learning. Massachusetts Institute of Technology. https://dspace.mit.edu/handle/1721.1/63059

Ariza, V. (2013). La investigación basada en la práctica: Una nueva perspectiva para la enseñanza del diseño. Revista Digital Universitaria, 14(7), NA. http://www.revista.unam.mx/vol.14/num7/art16/index.html

Aromaa, S., \& Väänänen, K. (2016). Suitability of virtual prototypes to support human factors/ergonomics evaluation during the design. Applied Ergonomics, 56, 11-18. https://doi.org/10.1016/j.apergo.2016.02.015

Cipollone, M., Schifter, C. C., \& Moffat, R. A. (2014). Minecraft as a Creative Tool. International Journal of Game-Based Learning, 4(2), 1-14. https://doi.org/10.4018/ijgbl.2014040101

Dalgarno, B., Gregory, S., Carlson, L., \& Tynan, B. (2013). A systematic review and environmental analysis of the use of $3 \mathrm{D}$ immersive virtual worlds in Australian and New Zealand Higher Education institutions (ISBN: 978-1-921597-56-5). University of New England. https://www.academia.edu/28810551/VWSSP_Report_V2_TD_200613_dehub

Dobrilova, T. (2020, July 2). How Much Is the Gaming Industry Worth in 2020? [+22 Powerful Stats]. TechJury. https://techjury.net/blog/gaming-industry-worth/\#gref

Ertmer, P. A., \& Newby, T. J. (1993). Behaviorism, Cognitivism, Constructivism: Comparing Critical Features From an Instructional Design Perspective. Performance Improvement Quarterly, 6(4), 50-72. https://doi.org/10.1111/j.1937-8327.1993.tb00605.x

Freina, L., \& Ott, M. (2015). A literature review on immersive virtual reality in education: state of the art and perspecivtes. In The International Scientific Conference eLearning and Software for Education (1)133141. Retrieved September 27, 2020, from https://www.itd.cnr.it/download/eLSE\%202015\%20Freina\%200tt\%20Paper.pdf

Häkkilä, J., Colley, A., Väyrynen, J., \& Yliharju, A.-J. (2018). Introducing Virtual Reality Technologies to Design Education. Seminar.net, 14(1), 1-12. Retrieved from https://journals.hioa.no/index.php/seminar/article/view/2584

Jensen, L., \& Konradsen, F. (2017). A review of the use of virtual reality head-mounted displays in education and training. Education and Information Technologies, 23(4), 1515-1529. 
https://doi.org/10.1007/s10639-017-9676-0

Mäkelä, M. A., \& Nimkulrat, N. (2011, May). Reflection and documentation in practice-led design research. The 4th Nordic Design Research Conference, Aalto University, Helsinki, Finland. https://www.researchgate.net/publication/277309368

Merchant, Z., Goetz, E. T., Cifuentes, L., Keeney-Kennicutt, W., \& Davis, T. J. (2014). Effectiveness of virtual reality-based instruction on students' learning outcomes in K-12 and higher education: A metaanalysis. Computers \& Education, 70, 29-40. https://doi.org/10.1016/j.compedu.2013.07.033

Piscitelli Altomari, A. G. (1). Realidad virtual y realidad aumentada en la educación, una instantánea nacional e internacional. Economía Creativa, (7), 34-65. Recuperado a partir de http://ciecpress.centro.edu.mx/ojs/index.php/CentroTI/article/view/325

Radianti, J., Majchrzak, T. A., Fromm, J., \& Wohlgenannt, I. (2020). A systematic review of immersive virtual reality applications for higher education: Design elements, lessons learned, and research agenda. Computers \& Education, 147, NA. https://doi.org/10.1016/j.compedu.2019.103778

Reiners, T., Wood, L. C., \& Gregory, S. (2014, November 24). Experimental study on consumer-technology supported authentic immersion in virtual environments for education and vocational training | Research UNE. University of New England (UNE).https://rune.une.edu.au/web/handle/1959.11/176133

Richardson, V. (2003). Constructivist Pedagogy. Teachers College Record, 105(9), $1623-1640$. https://doi.org/10.1046/j.1467-9620.2003.00303.x

Robinson, M. (2020, March 30). Teaching transferable real-time skills at the University of Hertfordshire. Unreal Engine. https://www.unrealengine.com/en-US/spotlights/teaching-transferable-real-time-skillsat-the-university-of-hertfordshire

Thompson, M. (2019, June 28). Education Reimagined Through Constructivism. [Video]. TED Talks Conferences.

https://www.ted.com/talks/michelle_thompson_education_reimagined_through_constructivism

Vlasova, H. (2020, September 12). The Future of VR \& AR in Education. Getting Smart. https://www.gettingsmart.com/2020/09/the-future-of-vr-ar-in-education/

Wijman, T. (2020, October 1). The World's 2.7 Billion Gamers Will Spend \$159.3 Billion on Games in 2020; The Market Will Surpass $\$ 200$ Billion by 2023. Newzoo. https://newzoo.com/insights/articles/newzoogames-market-numbers-revenues-and-audience-2020-2023/ 